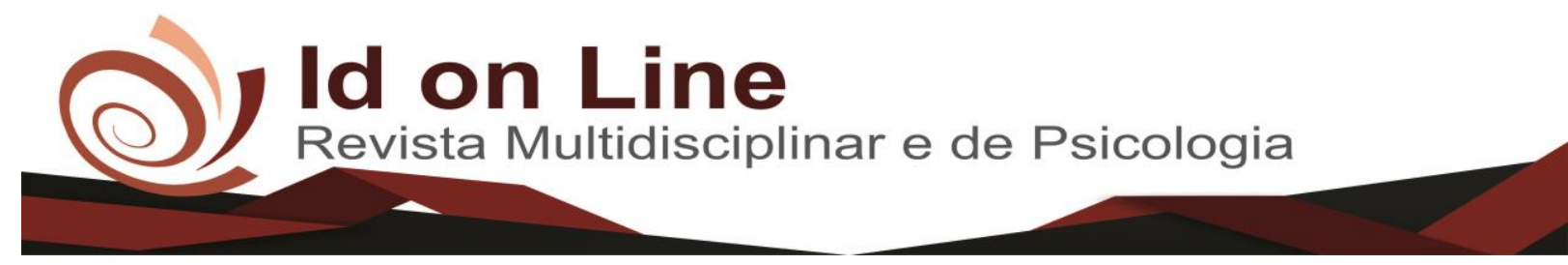

Relato de Caso

\title{
Implante imediato em área estética com grande recessão gengival: Relato de caso
}

\author{
Évellyn Pinheiro Santos Pereira ${ }^{1}$; Larissa Ledo Pereira Sant'Ana ${ }^{2}$
}

\begin{abstract}
Resumo: Os implantes imediatos com carga imediata são instalados logo após a exodontia, quando são instaladas próteses provisórias sobre os mesmos. Esta técnica cirúrgica vem mostrando um avanço significativo nos últimos anos, e quando bem indicados, são uma ótima solução a substituição de dentes perdidos. Dessa forma, o objetivo desse trabalho é relatar um caso clínico de implante imediato com provisionalização imediata em área estética com grande recessão gengival. No presente caso, a paciente apresentou insatisfação com a unidade 11 associado a uma grande recessão gengival, sendo proposto a extração do mesmo e a colocação do implante imediato, acompanhado com o enxerto de tecido conjuntivo, retirado da região do palato. Na mesma sessão clínica foi confeccionada a coroa provisória, com o objetivo de preservar a estética da paciente enquanto a mesma aguarda o tempo da osseaintegração, para, assim, realizar a prótese final. Baseada na metodologia descrita nesse relato de caso, é possível notar que após o período de 6 meses de acompanhamento clínico e radiográfico, houve uma melhora satisfatória nos tecidos periodontais. O tratamento foi realizado com o intuído de devolver uma melhor estética e função a unidade perdida.
\end{abstract}

Descritores: Implante dentário, estética, recessão gengival.

\section{Immediate Implant in Aesthetic Area with Large Gingival Recession: A Case Report}

\begin{abstract}
Immediate-loading Immediate Implants are installed shortly after the Exodontia, when temporary prostheses are installed on them. This surgical technique has been showing a significant advance in recent years, and when well indicated, are a great solution to replace missing teeth. Thus, the objective of this work is to report a clinical case of immediate implantation with immediate provision in aesthetic area with great gingival recession. In the present case, the patient presented dissatisfaction with the unit 11 associated with a large gingival recession, being proposed the extraction of the same and the placement of the immediate implant, accompanied with the graft of connective tissue, removed from the palate region. In the same clinical session, the provisional crown was made, in order to preserve the aesthetics of the patient while the patient waits for the time of osseointegration, in order to perform the final prosthesis. Based on the methodology described in this case report, it is possible to notice that after a period of 6 months of clinical and radiographic follow-up, there was a satisfactory improvement in the periodontal tissues. The treatment was carried out with the intention of returning a better aesthetic and function to the lost unit.
\end{abstract}

Keywords: Dental implant, aesthetic, gingival recession.

\footnotetext{
${ }^{1}$ Graduanda do curso de Odontologia da Faculdade Independente do Nordeste. Vitória da Conquista - BA, Brasil.

${ }^{2}$ Especialista e Mestre em Implantodontia e Docente do curso de Odontologia da Faculdade Independente do Nordeste, Vitória da Conquista - BA, Brasil. Contato: larissaledo@ hotmail.com
} 


\section{Introdução}

A estética do sorriso tem um valor social essencial e relevante na Odontologia. Dessa forma, ao sofrerem a perda de um elemento dentário, os pacientes desejam sua reabilitação de forma rápida e segura (OLIVEIRA et al., 2008). A técnica de instalação de implantes imediatamente após a extração dentária com carga imediata surgiu da necessidade de resultados mais rápidos e do nível de exigência estético elevado (VIANA, 2017).

O implante imediato com carga imediata representa um grande avanço tecnológico. Com eles, vêm os desafios de uma arquitetura gengival estética satisfatória e que alcance os resultados esperados pelo paciente submetido ao tratamento. Esse tratamento tem como objetivo reduzir o tempo de trabalho, além de preservar a estrutura óssea e o tecido gengival. O procedimento da colocação de implante após a extração apresenta um bom prognóstico (ZANNI et al., 2011).

A instalação imediata de implantes é um sucesso do ponto de vista da osseointegração. Do ponto de vista clínico, ocorre uma diminuição do número de cirurgias, uma vez que a extração dentária é feita no mesmo momento da instalação do implante. Assim, o paciente terá apenas uma fase pós-operatória. Para definir a real indicação deste tipo de reabilitação, deve-se levar em consideração alguns aspectos, pensando nos resultados estéticos e na reabilitação protética do caso clínico, tais como qualidade óssea, oclusão, hábitos parafuncionais e condição sistêmica do paciente. Também deve ser considerada a remodelação dos tecidos periimplantares, através de técnicas cirúrgicas de enxerto de tecido conjuntivo, visando à preservação do volume dos tecidos (MIGUEL et al., 2016).

A manutenção da estrutura periodontal e osso de suporte são um dos grandes desafios encontrados na reabilitação oral. Técnicas para a reabilitação imediata de dentes perdidos têm sido utilizadas na tentativa de obter maior previsibilidade e proservação nos tratamentos com implantes osseointegráveis. As técnicas minimamente invasivas para exodontia e continuidade da integridade do tecido periodontal, com a inserção imediata de implantes, seguida de provisionalização imediata, têm se mostrado como uma excelente alternativa na preservação da arquitetura ósseagengival (MATTOS et al., 2016).

Regiões estéticas com defeitos ósseos e recessões gengivais dificultam a realização de uma reabilitação com implantes, podendo impossibilitar a confecção de próteses estéticas. O 
comprometimento estético, como grandes recessões gengivais pode gerar a necessidade do uso de técnicas de enxerto gengival, para devolver volume e forma após o implante imediato (REIS et al., 2009).

A recessão gengival, definida como uma migração da margem gengival pode ter como consequência a exposição radicular apresentando uma aparência estética desagradável. O enxerto de tecido conjuntivo tem sido fortemente estudado, e com o aumento da demanda estética, houve um avanço no tratamento para recessões gengivais que mostram que além do recobrimento radicular a técnica é efetiva para promover ganho clínico de inserção e de tecido queratinizado (VENTURIM; JOLY; VENTURIM, 2011).

As próteses provisórias são essenciais em reabilitações protéticas, principalmente em região anterior, de forma que parâmetros estéticos devem ser considerados durante a sua confecção, como cor, forma e semelhança com a dentição natural, além da arquitetura e saúde dos tecidos adjacentes (COMMAR et al., 2017).

O objetivo desse trabalho é apresentar um relato de caso clínico no qual foi realizado um implante imediato com carga imediata após exodontia do elemento dentário 11, em região com grande recessão gengival. Para o sucesso estético do caso, foi necessário o uso de um enxerto de tecido conjuntivo, e a confecção da prótese provisória imediata, propiciando uma melhor estética e função.

\section{Relato de caso}

Paciente do gênero feminino, 33 anos, melanoderma, apresentou-se com a queixa principal de deficiência estética no elemento 11, o qual apresentava-se com prótese fixa unitária, dentossuportada, realizada há 8 anos.

Ao exame clínico observou-se uma grande recessão gengival do elemento dentário associado com migração apical do mesmo, causando uma desproporção da altura da coroa do elemento em relação aos dentes adjacentes (Figuras 01). 


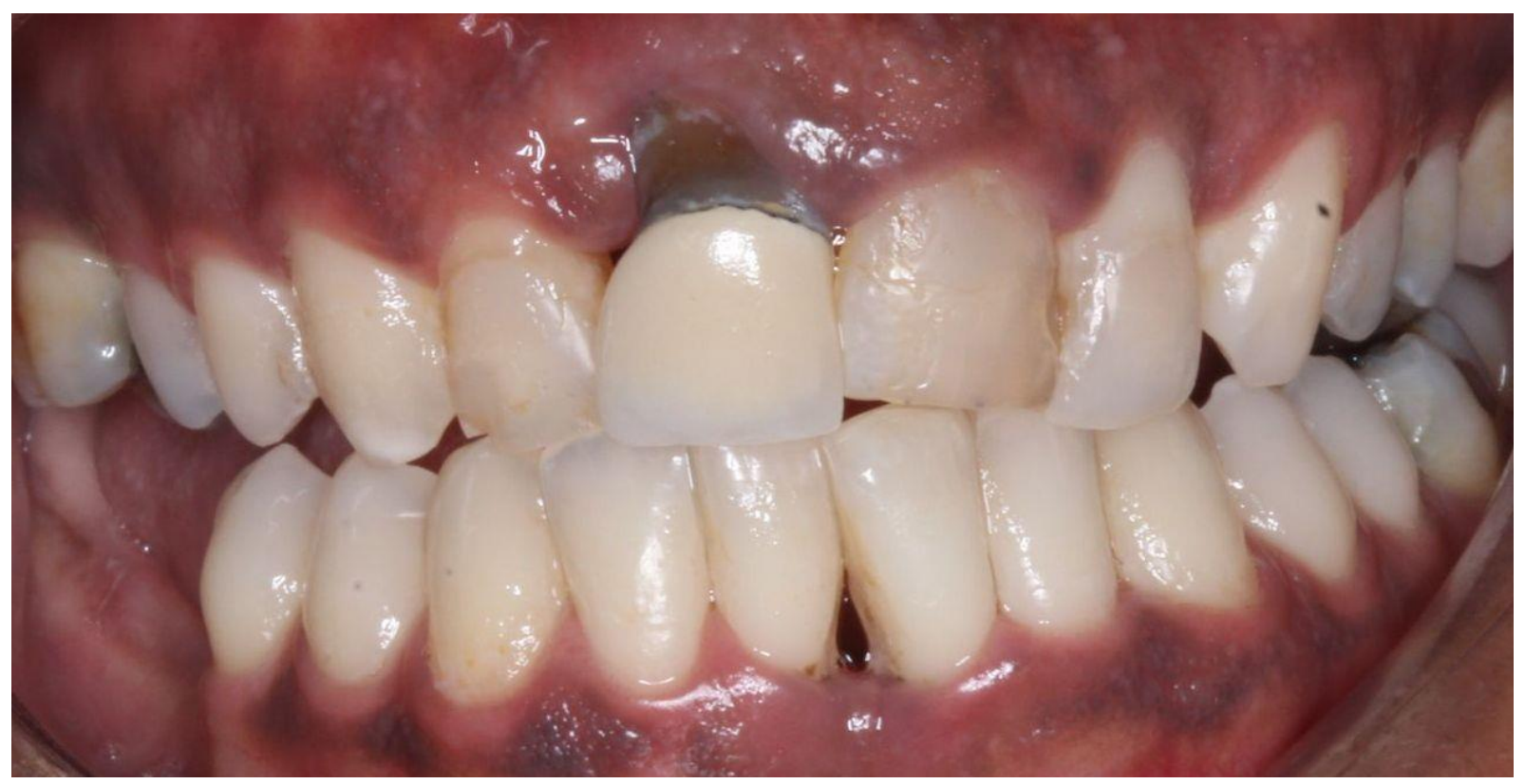

Figura 1- Imagem inicial, com grande recessão gengival.

Foram solicitadas radiografias periapicais, panorâmica e tomografia computadorizada de feixe cônico (TCFC), onde foi constatada a perda do elemento dentário, devido á migração apical e perda de inserção óssea. Estes exames de imagem, atualmente, têm permitido um planejamento extremamente preciso, facilitando a visualização e avaliação do local escolhido para a colocação do implante.

Após a documentação fotográfica, procedeu-se o planejamento integrado, protético e cirúrgico. Iniciou-se então a análise da tomografia (Figura 02), na qual foi verificada presença do osso residual suficiente para que o implante fosse colocado na posição protética ideal. Seguidamente foram solicitados exames laboratoriais de rotina, para descartar doenças sistêmicas, onde o paciente foi classificado como ASA I. 


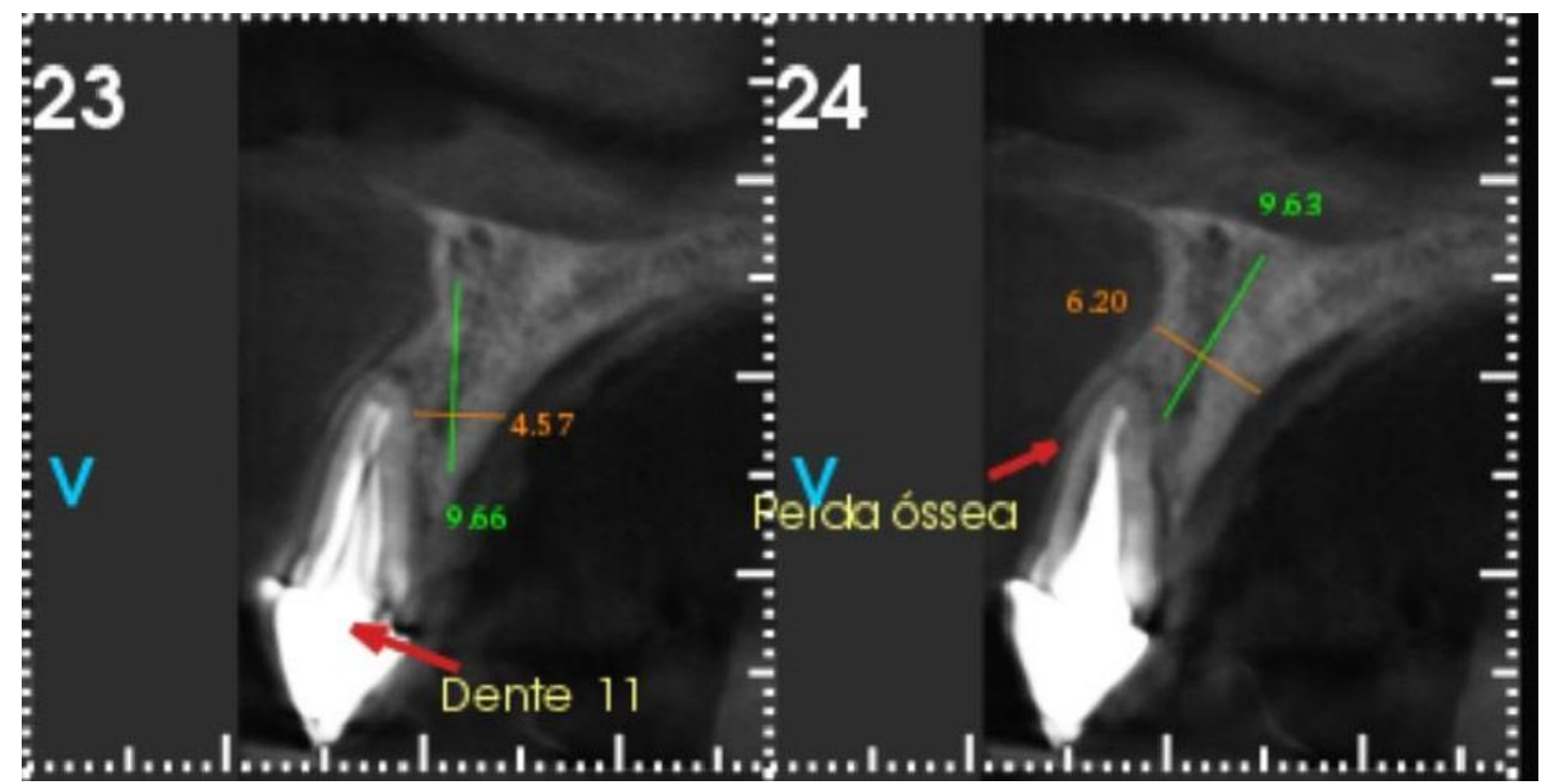

Figura 2- Analise Tomográfico.

Um mês antes da cirurgia, foi realizado um desgaste na porção vestibular da raiz do elemento 11, com o objetivo de promover um fechamento espontâneo dos tecidos ao redor da mesma, após este período, houve pequeno crescimento de tecido gengival.

Previamente à cirurgia, foi realizada a antibioticoterapia profilática, com a ingestão de 2 gramas de amoxicilina, 01 hora antes. Como medidas de assepsia extra oral foi utilizado o digluconato de clorexinia a $2 \%$, e intra oral, foi solicitado ao paciente bochechar por 1 minuto clorexidina a $0,12 \%$. O anestésico utilizado foi a mepivacaína $2 \%$ com epinefrina $1: 1000.000 \mathrm{UI}$.

Foi realizada a exodontia do elemento dentário com a técnica minimamente invasiva (Figura 03), onde o uso de periótomo foi fundamental para a preservação do tecido ósseo ao redor do dente. Essa abordagem, realizada com mínima destruição óssea, permitiu a colocação do implante na posição 3D ideal (straumann 3.3X10 mm) com torque de 32N (Figura 04). 


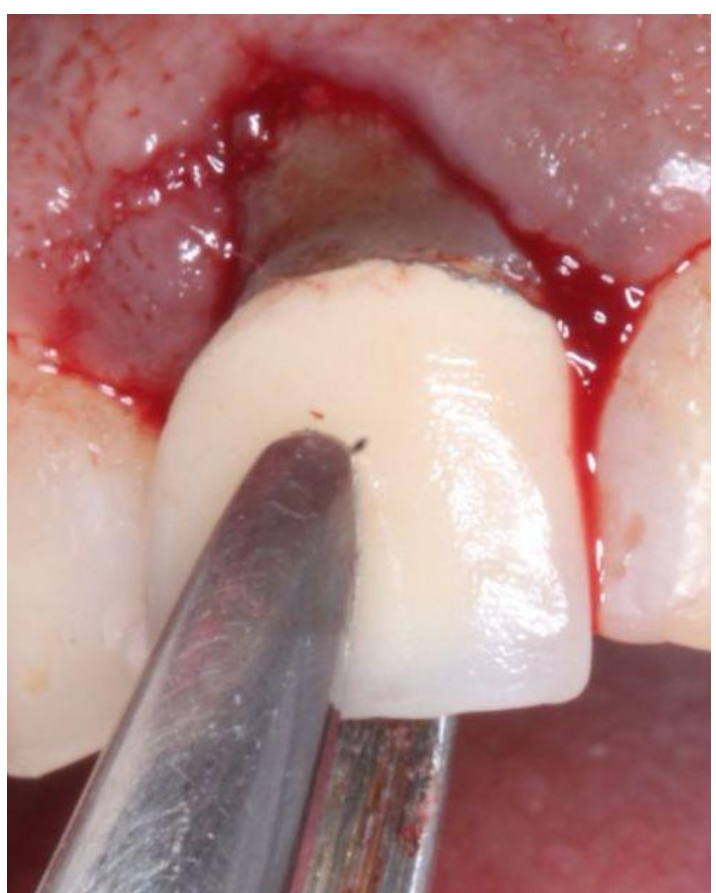

Figura 3- Exodontia do elemento dentário.

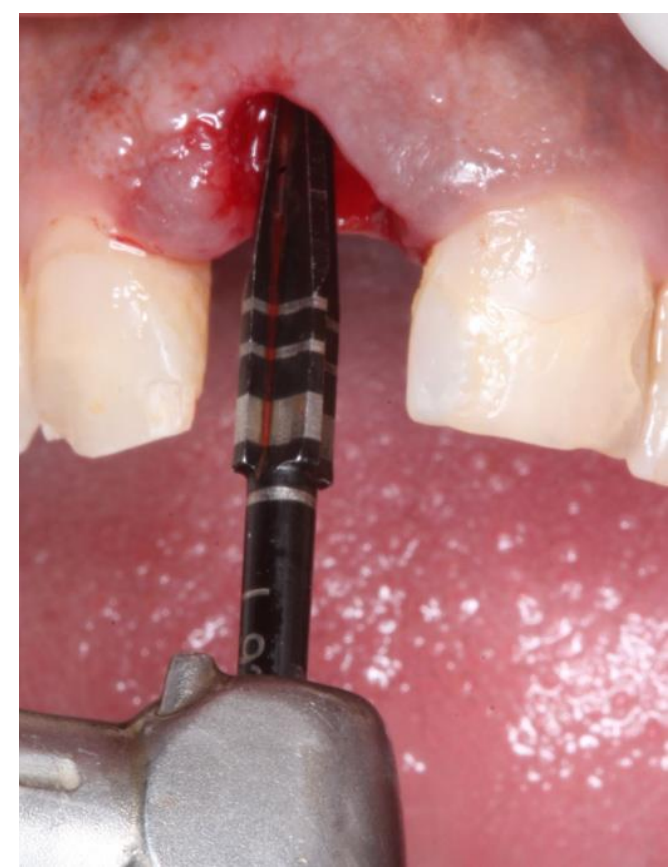

Figura 4- Broca utilizada para permitira a instalacão do implante.

Com o objetivo de ganhar altura e espessura da margem gengival, foi removido um enxerto conjuntivo da região do palato (Figura 05), e instalado na região vestibular do elemento dentário em questão (Figura 06). O conjunto foi suturado (Figura 07) e a prótese provisória foi instalada diretamente no implante. Após 15 dias, os tecidos e o implante apresentavam-se dentro da normalidade, assim a sutura foi removida (Figura 08).

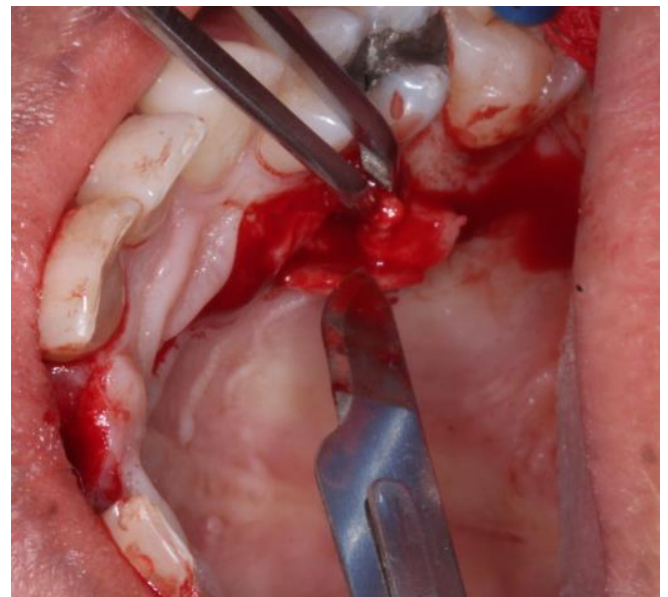

Figura 5- Enxerto conjuntivo removido da região do palato. 


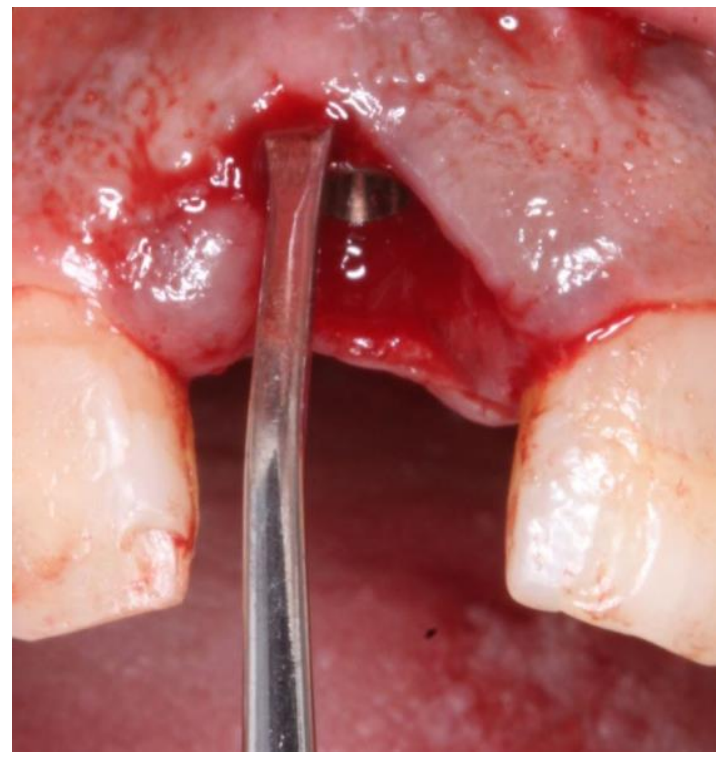

Figura 6- Instalação do enxerto conjuntivo na região vestibular.

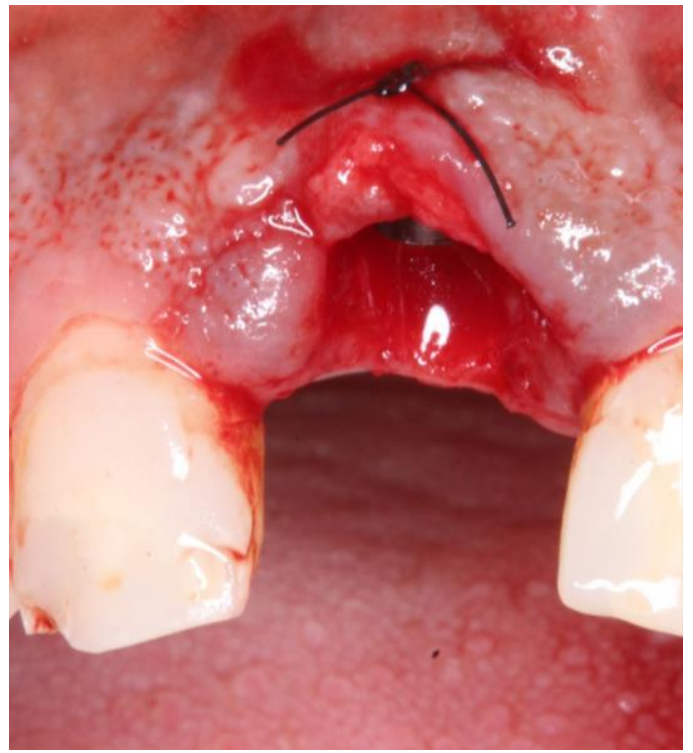

Figura 7- Conjunto suturado.

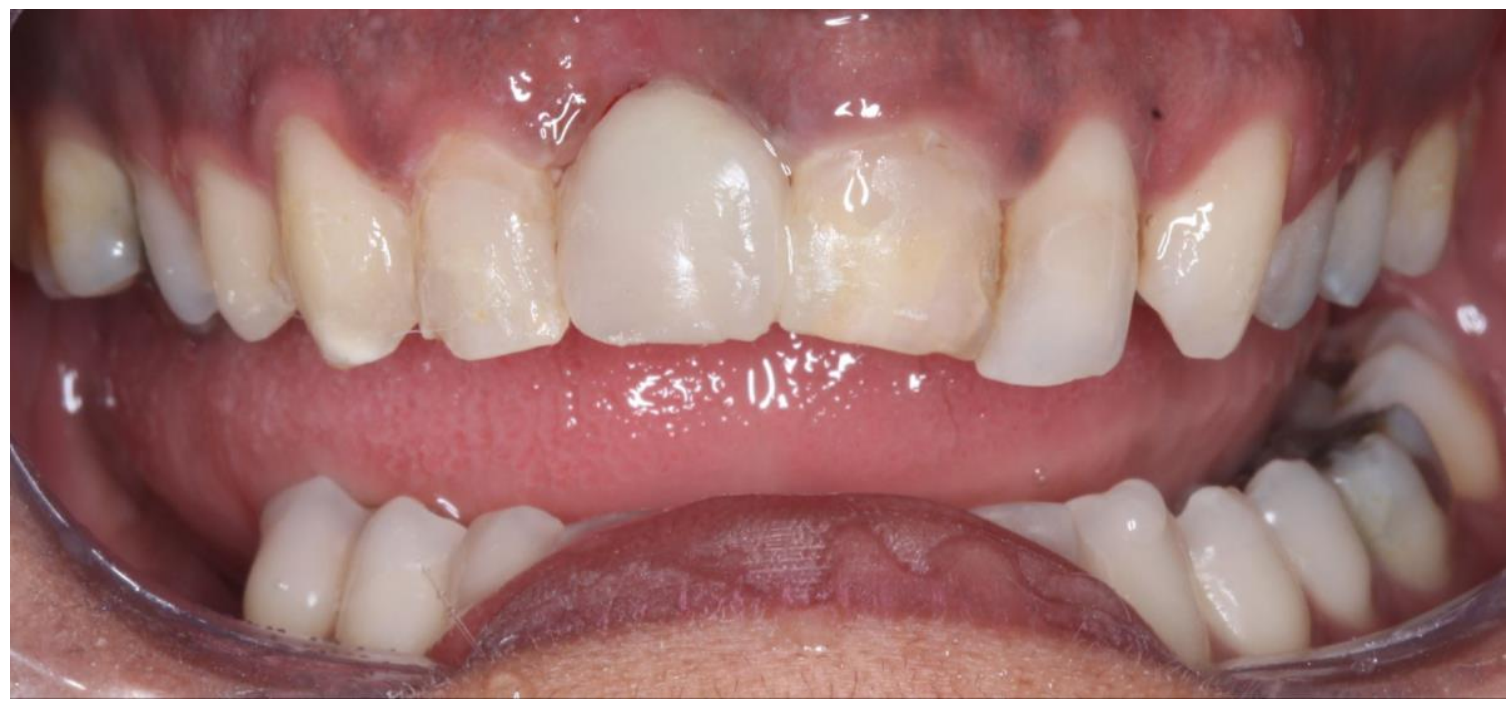

Figura 8- Prótese provisória.

A paciente foi acompanhada durante 6 meses, e após esse período será finalizada a parte da instalação protética, podendo ser observado resultados satisfatórios com o tratamento realizado. 


\section{Discussão}

Um sorriso seguindo os padrões estéticos tem ganhado destaque no processo de reabilitação oral, principalmente em regiões anteriores. Alguns autores discutem a elevada exigência dos pacientes dada a cobrança estética dos tempos atuais. Contudo os profissionais da Odontologia não devem deixar de levar em conta a manutenção do arcabouço periodontal e o osso de suporte durante o processo de reabilitação oral, afinal trata-se de um conjunto de elementos que devem ser analisados durante planejamento e execução de um tratamento (OLIVEIRA et al., 2008; MATOS et al., 2016).

A perda de um dente traz sérias consequências à saúde oral do indivíduo. Tendo em vista que o elemento dentário mantém um suporte ósseo e gengival, a sua ausência tende a promover a reabsorção do rebordo residual, diminuindo dessa forma a função mastigatória. Para além dessas alterações na cavidade, a perda de um dente pode alterar o sistema emotivo do paciente, diminuindo sua capacidade social, o que pode levá-lo inclusive a reclusão (AGOSTINHO et al., 2015; CANO et al., 2015; PROBST et al., 2016).

A paciente relatada neste caso, procurou o CD devido a sua insatisfação com a estética do elemento dentário anterior, com recessão e extrusão, buscando um tratamento que melhorasse seu sorriso e consequentemente sua autoestima. A recessão e a extrusão apresentadas no elemento 11 provavelmente estavam relacionadas à mal oclusão associada a inflamação local do elemento dentário. O conjunto destes fatores resultou em uma estética insatisfatória para a paciente.

A recessão gengival, principalmente em faces vestibulares, é considerada uma situação de grande destaque negativo para a estética. Segundo a literatura, esta pode ser definida como uma condição clínica onde tecido periodontal é deslocado em sentido apical com comitente exposição do elemento dentário (VENTURIM; JOLY; VENTURIM, 2011).

Há uma discussão, ainda, sobre as possíveis causas dessas recessões, sendo divididas em duas categorias: fatores primários, quando o agente causal não é inerente ao indivíduo como, por exemplo, trauma por escovação; e fatores secundários, quando a situação é pertencente ao próprio paciente, como um contato prematuro (VENTURIM; JOLY; VENTURIM, 2011; PROBST et al., 2016; MARINHO; CIMÕES; JAMELLI, 2007; ANDRADE et al., 2012). 
No presente relato de caso a paciente apresentava um elemento dentário com grande recessão gengival em área estética, necessitando de uma reabilitação que fosse eficaz. Após a constatação da perda do elemento dentário, foi selecionado como terapia o implante imediato após a exodontia, associado ao enxerto de tecido conjuntivo. Esta técnica tem a finalidade de aumentar a altura e a espessura da mucosa e corrigir as margens irregulares da mesma, daí a sua escolha para sanar a recessão apresentada (REINO et al., 2013).

Com intuito de resolver o problema da paciente, optou-se por um implante dentário na área do elemento 11 após a extração do remanescente dentário presente na região. É importante destacar que os implantes dentários surgiram nas últimas décadas como uma alternativa para perdas do elemento dentário. Eles são capazes de reabilitar não somente a estética como a função dentária. Autores somam também a devolução da autoestima do paciente (FLORENTINO; ATAÍDE; PEREIRA, 2012; CASTRO; CORAZZA, 2014; CARVALHO et al., 2006; TABUSE; CÔRREA; VAZ, 2014).

Além de um planejamento adequado da instalação do implante, o CD deve saber que as próteses provisórias são essenciais em reabilitações protéticas, principalmente em região anterior, de forma que parâmetros estéticos devem ser considerados durante a sua confecção, como cor, forma e semelhança com a dentição natural, além da arquitetura e saúde dos tecidos adjacentes (COMMAR et al., 2017).

No caso clínico utilizou-se a técnica de instalação do implante com carga imediata. Essa técnica consiste em colocação de uma prótese imediatamente à instalação do implante. Sendo importante para o caso, uma vez que se tratava de uma área muito estética. Estudos tem destacado o sucesso dessa técnica, envolvendo a avaliação do prognóstico dos tecidos moles adjacentes e ausência de danos ao tecido ósseo (MATIELLO; TRETIN, 2015).

\section{Conclusão}

O uso da técnica de instalação de implantes imediatos com carga imediata já é sacramentado na implantodontia, porém há de se ter atenção ao planejamento e ao manejo dos tecidos moles, para assim corrigir sequelas estéticas. A utilização da técnica e do tratamento

915 Id on Line Rev. Mult. Psic. V.12, N. 42, p. 907-918, 2018 - ISSN 1981-1179 Edição eletrônica em http: //idonline.emnuvens.com.br/id 
realizado trouxe resultados estéticos satisfatórios e funcionais, bem como possibilitou uma melhoria estética e da auto estima da paciente.

\section{Referências}

AGOSTINHO ACMG, CAMPOS ML, SILVEIRA JLGC. Edentulismo, uso de prótese e autopercepção de saúde bucal entre idosos. Revista de Odontologia da UNESP, v.44, n.2, p. 74-79. Campinas - $2015 . \quad$ SP, Disponível em: < http://www.scielo.br/scielo.php?script=sci_arttext\&pid=S1807-25772015000200074>. Acesso em 24 out. 2018.

ANDRADE LP, BISCARDE A, MOREIRA A, RIBEIRO E, BITTENCOURT S. Tratamento de dentes com recessão gengival e abrasão cervical. Revista Bahiana de Odontologia, v.3, n.1, p.86-89 Salvador - BA, 2012.

CANO CG, BORDA MG, ARCINIEGAS AJ, BORDA CX. Edentulism and dental prostheses in the elderly: impact on quality of life measured with EuroQol - visual analog scale (EQ-VAS). Acta de Odontologia Latinoamericano, v.28, n.2, p.149-155. 2015. Disponível em: <https://www.ncbi.nlm.nih.gov/pubmed/26355885>. Acesso em 24 out. 2018.

CARVALHO NB, GONÇALVES SLMB, GUERRA CMF, CARREIRO AFP. Planejamento em implantodontia: uma revisão contemporânea. Revista de Cirurgia e Traumatologia BucoMaxilo-Facial, v.6, n.4, p.17-22. 2006.

CASTRO HL, CORAZZA PH. Implante imediato em área estética - relato de caso com um ano de acompanhamento. Full Dental Science, v.5, n.19, p.422-428. 2014. Disponível em: < http://pesquisa.bvs.br/brasil/resource/pt/lil-726522>. Acesso em 24 out. 2018.

COMMAR BC, GOIATO MC, SILVA EV, BITENCOURT AB, SANTOS DM. Instalação de prótese provisória implantossuportada: relato de caso. Revista de Odontologia de Araçatuba, v.38, n.2, p. 32-35. Araçatuba - SP, 2017.

FLORENTINO FILHO ATC, ATAÍDE WS, PEREIRA AFV. O implante dentário como uma alternativa para pacientes periodontais: uma revisão de literatura. Revista Ciência e Saúde, v.14, n.1, p.53-50. Rio de Janeiro - RJ, 2012. Disponível em: $<$ http://www.periodicoseletronicos.ufma.br/index.php/rcisaude/article/view/1283>. Acesso em 24 out. 2018.

MARINHO EVS, CIMÕES R, JAMELLI SR. Recessão gengival na infância. International Jounal of Dentistry, v.6, n.4, p.113-116. Recife - PE, 2007. Disponível em: < https://periodicos.ufpe.br/revistas/dentistry/article/view/13893>. Acesso em 24 out. 2018. 
MATIELLO CN, TRETIN MS. Implante dentário com carga imediata na região anterior superior: relato de caso clínico. Revista da Faculdade de Odontologia, v.20, n.2, p.238-42. Curitiba $\quad-\quad 2015.2$ PR, Disponível em: http://seer.upf.br/index.php/rfo/article/download/4515/3549>. Acesso em 24 out. 2018.

MATTOS TB, GULINELLI JL, SANTOS PL, BRAGANÇA R, CERDEIRA F, MAYRINK LEM. Reabilitação imediata em área estética em alvéolo com grande comprometimento ósseo. Full Dental Science, v.7, n.26, p. 35-40. 2016. Disponível em: < http://www.sgponline.com.br/editoraplena/fullscience/sgp/Biblioteca/DOC/422_957_PT_3540_reabilitacao_imediata.pdf >. Acesso em 24 out. 2018.

MIGUEL JR H, GENOVESE W, BELTRÃO CSB, KASSARDJIAN F, CERRI A. Implante imediato associado ao enxerto de tecido conjuntivo: relato de caso clínico. Revista da Associação Paulista de Cirurgia Dental, v.70, n3, p. 312-316. São Paulo - SP, 2016. Disponível em: < http://revodonto.bvsalud.org/pdf/apcd/v70n3/a15v70n3.pdf >. Acesso em 24 out. 2018.

OLIVEIRA AC, SOUZA JR, THOMÉ G, MELO ACM, SARTORI IAM. Implante imediato unitário em função imediata - relato de caso. Revista da Faculdade de Odontologia, v.13, n.1, p. 69-74. Curitiba - PR, 2008. Disponível em: < http://www.jrenato.com.br/artigos/003.pdf>. Acesso em 24 out. 2018.

PROBST LF, AMBROSANO GMB, CORTELLAZZI KL, GUERRA LM, DA SILVA MR, Tomar $\mathrm{S}$ et al. Fatores associados aos sentimentos decorrentes da perda dentária total e às expectativas de reposição protética em adultos e idosos. Caderno de Saúde Coletiva, v.24, n.3, p.347-354. Rio de Janeiro - RJ, 201. Disponível em: < http://www.scielo.br/scielo.php?pid=S1414462X2016000300347\&script=sci_abstract\&tlng=pt>. Acesso em 24 out. 2018.

REINO DM, NOVAES JR ABN, GRISI MFM, MAIA LP, SOUZA SLS. Palatal Harvesting Technique Modification for Better Control of the Connective Tissue Graft Dimensions. Brazilian Dentistry Journal, v.24, n.6, p.565-568. 2013. Disponível em: < http://www.scielo.br/scielo.php?pid=S0103-64402013000600565\&script=sci_arttext $>$. Acesso em 24 out. 2018.

REIS AC, MARCANTONIO JR E, MARGONAR R, SILVA LJ. Prevenção estética com enxerto conjuntivo e biomaterial. Revista Gaúcha de Odontologia, v.57, n.2, p.235-239. Porto Alegre $\quad-\quad$ RS, 2009. Disponível em: https://www.researchgate.net/profile/Rogerio_Margonar/publication/26636797_Prevencao_es tetica_com_enxerto_conjuntivo_e_biomaterial/links/0046351a75f455e8be000000/Prevencaoestetica-com-enxerto-conjuntivo-e-biomaterial.pdf>. Acesso em 24 out. 2018.

TABUSE HE, CÔRREA CB, VAZ LG. Comportamento biomecânico do sistema prótese/implante em região anterior de maxila: análise pelo método de ciclagem mecânica. Revista de Odontologia da UNESP, v.43, n.1, p. 46-51. São Paulo - SP, 2014. Disponível em: 
< http://www.scielo.br/pdf/rounesp/v43n1/1807-2577-rounesp-43-01-00046.pdf >. Acesso em 24 out. 2018.

VENTURIM RTZ, JOLY JC, VENTURIM LR. Técnicas cirúrgicas de enxerto de tecido conjuntivo para o tratamento da recessão gengival. Revista Gaúcha de Odontologia, v.59, p.147-152. Porto Alegre - RS, 2011.Disponível em: < http://revodonto.bvsalud.org/pdf/rgo/v59s1/a20v59s1.pdf>. Acesso em 24 out. 2018.

VIANNA KC. Instalação de implantes imediatos contíguos em região estética: relato de caso com 30 meses de acompanhamento. Revista da Faculdade de Odontologia, v.47. 2017. Disponível em: < http://www.ijosd.uff.br/index.php/n37/article/view/349>. Acesso em 24 out. 2018.

ZANNI SR, ALVES RA, KORB SHB, RIVALDO EG, FRASCA LCF. Colocação de implante imediato após exodontia: relato de caso clínico. Revista de Odontologia Clínica e Científica, v.10, n.3, p.281-284. Recife - PE, 2011. Disponível em: < http://webcache.googleusercontent.com/search?q=cache:1 y471KjvaTkJ:revodonto.bvsalud.org /scielo.php\%3Fscript\%3Dsci_arttext\%26pid\%3DS1677-

$38882011000300018+\& c d=2 \& h l=p t-B R \& c t=c l n k \& g l=b r>$. Acesso em 24 out. 2018.

\section{Como citar este artigo (Formato ABNT):}

PEREIRA, Évellyn Pinheiro Santo; SANT’ANA, Larissa Ledo Pereira. Implante imediato em área estética com grande recessão gengival: Relato de caso. Id on Line Rev.Mult. Psic., 2018, vol.12, n.42, p. 907-918. ISSN: 1981-1179.

Recebido: 24/10/2018;

Aceito: 26/10/2018 